David H.W. Wong MB BS FRCPC,

Ernest Koehrer MD FRCPC,*

Hugo F. Sutton MB BS FRCs, $\nmid$ Pamela Merrick BSN*

\title{
A modified retrobulbar block for eye surgery
}

A modified retrobulbar block (MRB) using a single superomedial injection was compared with the classical retrobulbar block $(R B)$ and peribulbar block (PB) in a randomized, prospective, surgeon-blinded study involving 150 patients undergoing cataract surgery. No serious complication occurred in any of the patients, The MRB produced higher rates of total akinesia in the orbicularis and all the extraocular muscles, which were statistically significant for the orbicularis, superior, inferior and lateral rectus and oblique muscles when compared with $R B$, and for the superior rectus and oblique muscles when compared with PB. MRB required less supplemental blocks, provided good operating conditions for the surgeon, and achieved high patient acceptance. It is concluded that $M R B$ is a useful alternative method of ocular block for cataract surgery.

Le bloc rétrobulbaire modifié (BRM) à une seule injection supéro-interne est comparé au bloc rétrobulbaire classique (BR) et au bloc péribulbaire (BP). Létude randomisée, prospective, à lïnsu du chirurgien comprend 150 patients opérés pour cataracte. La chirurgie se déroule sans complications. Le BRM produit plus d'akinésie totale de l'orbiculaire et de tous les muscles extra-oculaires: elle est significative pour l'orbiculaire, les muscles droits inférieurs, supérieurs, latéraux et les muscles obliques comparativement au BP. Le BRM requiert moins souvent de supplément anesthésique, fournit des bonnes conditions opératoires et est bien accepté par le patient. On conclut que le BRM représente une alternative valable pour la chirurgie oculaire.

\section{Key words}

ANAESTHETIC TECHNIQUES: regional: retrobulbar; SURGERY: ophthalmic.

From the Departments of Anaesthesia* and Ophthalmology, $\dagger$ Faculty of Medicine, University of British Columbia, Vancouver, British Columbia

Address correspondence to: Dr. David H.W. Wong, Department of Anaesthesia, Vancouver General Hospital, Room 3200, 910 West 10th Avenue, Vancouver, British Columbia, Canada V5Z 4E3 Accepted for publication I6th February, 1993.
Cataract surgery is commonly performed as an outpatient procedure and with regional anaesthesia. ${ }^{1-3}$ The advantages of this approach include less disruption to the patient's physiology, ${ }^{4}$ rapid return to normal routines, ${ }^{2,3}$ better utilization of hospital beds and economy. Retrobulbar block (RB) and peribulbar block (PB) are the two most frequently used techniques.

Retrobulbar block was first described in 1884 by Knapp who performed an enucleation of an eyeball by injecting cocaine behind the eye. ${ }^{5}$ The introduction of better local anaesthetic agents has made RB an effective and popular choice for most ophthalmic surgical procedures. However, akinesia of the orbicularis muscle may not be adequate, and facial nerve block or orbital margin block is often used to immobilize the eyelids. The blind insertion of a needle into the orbit may occasionally traumatize neural and vascular structures or cause systemic complications, including ocular perforation, ${ }^{6-8}$ optic nerve damage, ${ }^{9,10}$ retrobulbar venous or arterial haemorrhage, ${ }^{11-15}$ contralateral amaurosis, ${ }^{16,17}$ brain-stem anaesthesia, ${ }^{18-21}$ grand mal seizure, ${ }^{22}$ respiratory arrest, ${ }^{23-25}$ and cardiac arrest. ${ }^{26}$ Fortunately, serious complications are rare. ${ }^{27}$ Nonetheless, $\mathrm{RB}$ continues to be the most commonly used technique.

Peribulbar block, with dual injections of anaesthetic solution outside the muscle cone, is an alternative approach which is believed to reduce the chance of needle penetration of the globe or traumatizing the neurovascular structures. ${ }^{3,28-31}$ This technique involves injection at two sites, uses a greater volume of anaesthetic solution, has a slower onset, and requires prolonged pressure on the orbit to optimize the orbital pressure and the quality of anaesthesia and akinesia. Peribulbar block also provides adequate lid block. However, serious complications such as globe perforation can still occur. ${ }^{32-35}$

The requirements of regional anaesthesia for cataract extraction are analgesia, akinesia and optimal orbital pressure. 3,36 There is controversy in the literature of the relative merits of the retrobulbar versus the peribulbar blocks. ${ }^{37-41}$ In a large series of cases, the incidence of inadequate akinesia which required block supplementation was around $20-25 \% .^{3}$ All cataract surgery at Vancouver General Hospital (VGH) Eye Care Centre (ECC) is performed under regional anaesthesia. Our experience in the first six months of operation in 1988 showed a comparable rate of block supplementation. 
Block supplementation is undesirable. The dual injection sites used in PB increases patient discomfort, anxiety and risk of complications. A modified approach to retrobulbar anaesthesia using a single superomedial injection is proposed. This modified retrobulbar block (MRB) does not require redirection of the needle around the equator of the globe and thus minimizes the possibility of globe perforation, particularly in highly myopic eyes. It does not require additional facial nerve block that is frequently used in the classical RB technique and is associated with a low supplementation rate.

A randomized prospective, surgeon-blinded study was conducted to compare MRB with the classical RB and $\mathrm{PB}$, in regard to (1) immobilization of the individual extraocular muscles, (2) immobilization of the orbicularis oculi, (3) incidence of block supplementation, (4) surgical conditions with respect to analgesia, akinesia and low globe pressure, (5) patient acceptance, and (6) associated complications.

\section{Methods}

The study was approved by the Ethics Committees of the University of British Columbia and the Vancouver General Hospital. All patients, of one surgeon, having cataract surgery at the VGH-ECC were recruited into the study after informed consent was obtained. No patients were excluded. One hundred and fifty patients were randomly assigned (by draw) to one of the three block techniques, resulting in 50 patients in each group.

All patients received the same standard care. The preoperative history, physical examination and appropriate laboratory data (ECG, CBC, electrolytes) were obtained before surgery. During the block procedure, ECG, pulse oximetry, and non-invasive blood pressure were monitored. The anxiety level of the patient on arrival was graded by the anaesthetist as calm, mildly to moderately anxious, and very anxious.

The anaesthetic block was performed approximately 30 to $\mathbf{4 0} \mathrm{min}$ before surgery. The same anaesthetic mixture was used for all blocks, the final concentration being bupivacaine $0.375 \%$, lidocaine $1 \%$ and 7.5 units hyaluronidase per $\mathrm{ml}$. No epinephrine was added. The anaesthetic blocks were performed with the patients resting in a $45^{\circ}$ reclined position on a dental chair with the eye gazing in neutral position at a marker placed on the ceiling. One drop of tetracaine $0.5 \%$ was deposited on the conjunctiva. A disposable 27 gauge $35 \mathrm{~mm}$ needle was used for all blocks.

The block technique was randomized by having the attending nurse draw the allocation from an envelope.

Retrobulbar block

An inferolateral approach was used, with the needle in- serted through the lower lid, at a point between the lateral one-third and medial two-thirds, to a depth of about 25 $\mathrm{mm}$, and then angled up and medially toward the apex of the orbit to a depth of about 33-35 mm (Figure A). Four $\mathrm{ml}$ of the anaesthetic mixture were deposited.

\section{Peribulbar block}

This consisted of two injections. The first was an inferolateral injection of $4 \mathrm{ml}$, with the needle inserted through the lower lid similar to the retrobulbar approach, but advanced only slightly past the equator of the globe to a total depth of $25 \mathrm{~mm}$. After two minutes, the needle was inserted superiomedially through the upper lid at a point midway between the medial canthus and the supraorbital notch, and advanced in the sagittal plane to a depth of about $20 \mathrm{~mm}$, where $3 \mathrm{ml}$ of the anaesthetic mixture were deposited (Figure B).

\section{Modified retrobulbar block (study group)}

This consisted of a single needle insertion superomedially through the upper lid at a point midway between the medial canthus and the supraorbital notch, and advanced slowly in the sagittal plane to a depth of $32-33 \mathrm{~mm}$ (Figure C). There should be no resistance to the passage of the needle. Four $\mathrm{ml}$ of anaesthetic solution were deposited. As the needle was withdrawn, an additional 0.5 $\mathrm{ml}$ were injected. Following all block injections, a Super Pinkie ball was applied to reduce the intraocular pressure.

Ten minutes after completion of the block, the eye was examined by the anaesthetist and the attending nurse together. The ability of the orbicularis oculi, superior rectus, inferior rectus, medial rectus, lateral rectus, and oblique muscles to move was graded as total akinesia, a flicker of movement, some movement or full movement. The presence or absence of conjunctival oedema or haemorrhage was noted. Numbness of the nose, cheek, lips or gum was also looked for. The pressure of the globe was manually assessed and compared with the opposite eye. Inadequate akinesia was treated by supplemental retrobulbar or peribulbar injection of 2-3 ml of the same anaesthetic mixture, and residual orbicularis movement was obliterated with van Lint facial nerve block. Eye drops prescribed by the surgeon (flurbiprofen $0.03 \%$, phenylephrine $2.5 \%$, and cyclopentolate $1 \%$ ) were also given. The Super Pinkie ball was reapplied until the patient went into the operating room. Sedation with small doses of intravenous midazolam was used only when necessary.

The patient was escorted to the operating room within 20 to $40 \mathrm{~min}$ of block administration. The face was cleaned and draped by the scrub nurse before the surgeon entered the operating room. The surgeon was blinded as to the type of anaesthetic block used. He graded akinesia, analgesia and pressure of the globe separately as op- 


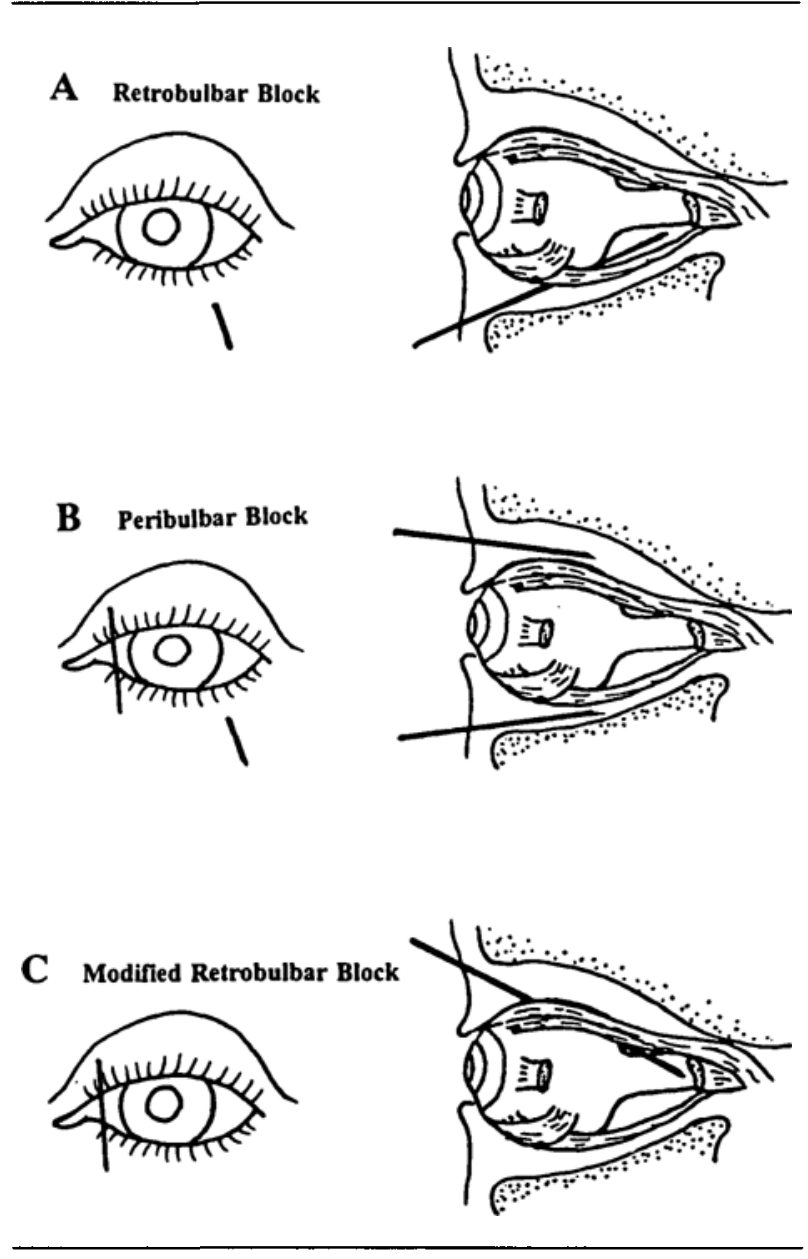

FIGURE Needle position of the three ocular block techniques.

timal, not optimal but able to proceed, or not optimal and unable to proceed. He also recorded the following information: supplementation in the operating room, complications related to the anaesthetic, discomfort or pain due to injection of antibiotic drug at the conclusion of surgery.

Within five minutes of the end of surgery, the patients were interviewed regarding their acceptance of the anaesthetic, presence or absence of pain or discomfort, and whether or not they would have the same anaesthetic if they needed to return for eye surgery in the future. Any comments that the patient made regarding the anaesthetic were recorded. The patients were usually discharged within $30 \mathrm{~min}$ of surgery after instructions on postoperative care of the eye were given.

All patients were seen by the surgeon on the morning after surgery in his office for follow-up, and the presence of any complication was noted.

The data were analyzed with the computer program NCSS (Number Cruncher Statistical System). All the cat-
TABLE I Patient demographics

\begin{tabular}{llll}
\hline & $R B$ & $P B$ & $M R B$ \\
\hline Patients & 50 & 50 & 50 \\
Male/female & $24 / 26$ & $18 / 32$ & $19 / 31$ \\
Age & & & \\
- Range & $21-92$ & $23-90$ & $38-95$ \\
- Median & 71.5 & 74 & 73.5 \\
ASA & & & \\
- I & 16 & 17 & 15 \\
- II & 24 & 20 & 23 \\
- III & 10 & 12 & 12 \\
- IV & 0 & 1 & 0 \\
\hline
\end{tabular}

egorical variables were expressed as counts or percentages and analyzed with chi-square tests with some categories condensed to increase cell frequencies when necessary. In some cases Fisher's exact test was used when expected values cell frequencies were less than five. Bonferroni's correction was used for multiple intergroup comparisons in contingency tables. The one continuous variable, age, was found to be skewed to the left in all groups and was therefore expressed as medians and ranges. A Kruskal-Wallis test was done to determine if there were any differences in age between groups. $P<0.05$ was considered significant, except where Bonferroni's correction reduced alpha to 0.0166 .

\section{Results}

No patient was excluded from and no patient refused to participate in the study.

\section{Patient demographics}

There was a total of 150 patients, with 50 in each of the three groups. The sex, age and ASA physical status distributions are shown in Table I. There were no significant differences in the level of anxiety among patients in the three groups.

\section{Akinesis and block supplementation}

The degree of immobilization of the orbicularis and extraocular muscles at ten minutes after administration of the anaesthetic blocks is summarized in Table II. There was no difference between the RB and PB groups in immobilizing the superior, inferior and lateral rectus muscles. The PB group achieved more total akinesia of the orbicularis oculi $(P=0.00001)$, medial rectus $(P<0.05)$ and obliques $(P<0.01)$ than the RB group.

Following MRB, total akinesia was obtained in $94 \%$ of orbicularis muscle, $92 \%$ of superior rectus, $90 \%$ of inferior rectus, $92 \%$ of medial rectus, $90 \%$ of lateral rectus, and $88 \%$ of oblique muscles. When compared with 
TABLE II Akinesia ten mintues after block

\begin{tabular}{|c|c|c|c|}
\hline & $R B$ & $P B$ & $M R B$ \\
\hline \multicolumn{4}{|l|}{ Orbicularis oculi } \\
\hline - Total akinesia & $23(46 \%)$ & $43(86 \%)^{*}$ & $47(94 \%)^{*}$ \\
\hline - Flicker & 1 & 2 & 2 \\
\hline - Some movement & 8 & 4 & 0 \\
\hline - Full movement & 18 & 1 & 1 \\
\hline \multicolumn{4}{|l|}{ Superior rectus } \\
\hline - Total akinesia & $30(60 \%) \dagger$ & $37(74 \%) \dagger$ & $46(92 \%)$ \\
\hline - Flicker & 8 & 7 & 2 \\
\hline - Some movement & 10 & 5 & 1 \\
\hline - Full movement & 2 & 1 & 1 \\
\hline \multicolumn{4}{|l|}{ Inferior rectus } \\
\hline - Total akinesia & $31(62 \%) \dagger$ & $39(78 \%)$ & $45(90 \%)$ \\
\hline - Flicker & 11 & 6 & 3 \\
\hline - Some movement & 5 & 4 & 1 \\
\hline - Full movement & 3 & 1 & 1 \\
\hline \multicolumn{4}{|l|}{ Medial rectus } \\
\hline - Total akinesia & $39(78 \%)$ & $46(92 \%)$ & $46(92 \%)$ \\
\hline - Flicker & 5 & 1 & 2 \\
\hline - Some movement & 2 & 2 & 1 \\
\hline - Full movement & 4 & 1 & 1 \\
\hline \multicolumn{4}{|l|}{ Lateral rectus } \\
\hline - Total akinesia & $34(68 \%) \dagger$ & $37(74 \%)$ & $45(90 \%)$ \\
\hline - Flicker & 4 & 7 & 1 \\
\hline - Some movement & 8 & 5 & 3 \\
\hline - Full movement & 4 & 1 & 1 \\
\hline \multicolumn{4}{|l|}{ Obliques } \\
\hline - Total akinesia & $25(50 \%)$ & $40(80 \%)^{*}$ & $44(88 \%)^{*}$ \\
\hline - Flicker & 17 & 5 & 5 \\
\hline - Some movement & 6 & 4 & 0 \\
\hline - Full movement & 2 & 1 & 1 \\
\hline
\end{tabular}

${ }^{*} P<0.0166$ vs. $\mathrm{RB}$ group.

$\dagger P<0.0166$ vs MRB group.

$\mathrm{RB}$, this was significant for orbicularis $(P<0.0001)$, superior rectus $(P<0.001)$, inferior rectus $(P<0.05)$, lateral rectus $(P<0.001)$, and oblique muscles $(P<$ $0.0001)$. When compared with $P B$, this was significant for both the superior rectus $(P<0.05)$ and oblique muscles $(P<0.05)$.

The overall incidence of block supplementation for inadequate akinesia of the extraocular muscles was $14.7 \%$ for all techniques $-26 \%$ in the RB group, $10 \%$ in the PB group, and $8 \%$ in the MRB group (Table III). Supplementation rates were higher for the RB group than in the PB group ( $P=0.00001)$ and in the MRB group $(P=0.00001)$. There was no difference in supplementation rates between $\mathrm{PB}$ and MRB groups.

\section{Side effects and complications}

There was no retrobulbar haemorrhage, perforation of the globe, brain-stem anaesthesia, respiratory or cardiac complications, or anaesthesia spreading to the opposite eye in any patient. All blocks provided satisfactory operating conditions, and no addition local anaesthetic in-
TABLE III Block supplementation before entering OR

\begin{tabular}{lcll}
\hline & $R B$ & $P B$ & $M R B$ \\
\hline Incidence & & & \\
- No supplementation & $22(44 \%)$ & $44(88 \%)$ & $46(92 \%)$ \\
- For extraocular M. & $13(26 \%)$ & $5(10 \%)^{*}$ & $4(8 \%)^{*}$ \\
- For orbicularis M. & $15(30 \%)$ & $1(2 \%)$ & 0 \\
& & & \\
Type of supplementation & $1 \mathrm{RB} \dagger$ & $3 \mathrm{RB}$ & $1 \mathrm{RB}$ \\
& $12 \mathrm{MRB}$ & $2 \mathrm{MRB}$ & $2 \mathrm{MRB}$ \\
& $0 \mathrm{~PB}$ & $0 \mathrm{~PB}$ & $1 \mathrm{~PB}$ \\
& $15 \mathrm{Rim} \dagger$ & $1 \mathrm{Rim}$ & O Rim \\
\hline
\end{tabular}

$* P<0.00001$ compared with RB group.

tOne patient received both $\mathrm{RB}$ and orbital rim block supplementation.

TABLE IV Complications

\begin{tabular}{llll}
\hline & $R B$ & $P B$ & $M R B$ \\
\hline Conj oedema & 2 & 8 & 6 \\
Conj haemorrhage & 1 & 1 & 1 \\
Retrobulbar Haem & 0 & 0 & 0 \\
Sedation & 1 & 0 & 0 \\
\hline
\end{tabular}

jection was required in any patient intraoperatively. Only one patient, in the RB group, required sedation.

There was no difference in the incidence of conjunctival oedema and minor conjunctival haemorrhage between the groups (Table IV). No patient developed ecchymosis of the lids. There was no difference in the incidence of extraocular numbness between the RB group and the MRB group. The $\mathrm{PB}$ group had more extraocular numbness than the RB group $(P<0.05)$ and the MRB group $(P<0.01)$ (Table V).

All, except one patient (small orbit, in RB group, with a moderate pressure), had soft eyes before entering the operating room. There was no difference among the three groups.

No procedure was delayed because of inadequate block, supplementation, high orbital pressure or other complications.

\section{Surgeon's assessment}

The surgeon's evaluation of analgesia, akinesia and orbital pressure intraoperatively is shown in Table VI. All cases were completed successfully without complications. No patient required additional anaesthetic or sedation in the operating room. Optimal analgesia was obtained in all patients in the MRB group. There were two patients in the RB group and one in the PB group that felt the initial incision or pulling of the globe. None of these three patients had received supplemental blocks (RB or MRB) prior to surgery. All were adequately treated with two 
TABLE V Extraocular numbness

\begin{tabular}{lccc}
\hline & $R B$ & $P B$ & $M R B$ \\
\hline Cheek & 2 & 2 & 1 \\
Nose & 8 & 20 & 9 \\
Lip & 6 & 13 & 5 \\
Gum & 1 & 5 & 5 \\
No extraocular numbness & $36^{*}$ & 24 & $39 \dagger$ \\
\hline
\end{tabular}

$* P=0.0143$ compared with $\mathrm{PB}$ group.

$\dagger P=0.0019$ compared with $\mathrm{PB}$ group.

TABLE VI Conditions for surgery

\begin{tabular}{lcll}
\hline & $R B$ & $P B$ & $M R B$ \\
\hline Optimal analgesia & $43(86 \%)^{*}$ & $49(98 \%)$ & $50(100 \%)$ \\
Optimal akinesia & $47(94 \%)$ & $47(94 \%)$ & $44(88 \%)$ \\
Optimal pressure & $50(100 \%)$ & $50(100 \%)$ & $50(100 \%)$ \\
Felt antibiotic injection & $8(16 \%)$ & $8(16 \%)$ & $5(10 \%)$ \\
\hline
\end{tabular}

$* P=0.0124$ compared with MRB group.

drops of topical tetracaine $0.5 \%$ on the cornea. The incidence of less than optimal analgesia was higher in the RB group compared to the MRB group $(P<0.05)$. There was no difference between the $P B$ and MRB groups, and between the RB and PB groups. Eight patients in each of the RB and PB groups, and five patients in the MRB group felt the antibiotic injection at the end of surgery $(P=\mathrm{NS})$. Further questioning of the patients revealed that none felt pain, and they were only aware of the pressure of injection.

No patient experienced prolonged anaesthesia, ptosis, akinesia of extraocular muscles or amaurosis at the time of follow-up at the surgeon's office the next morning.

\section{Patients' evaluation}

No patient complained of severe or intolerable pain during administration of the local block. More patients volunteered that they had encountered no pain during administration of block in the MRB group (60\%) than in the PB group (36\%) $(P<0.05)$. There was no difference between MRB and RB groups or between RB and PB groups (Table VII).

No patient in the MRB felt pain during surgery. Five patients in the RB group and four in the PB groups felt some discomfort or mild pain either at the start or at the end of surgery. None of the patients was distressed by this, and was easily made comfortable by two drops of tetracaine $0.5 \%$ on the cornea.

When asked if they would have the same anaesthetic block if they should require eye surgery in the future, only one patient in the RB and one in the PB group would prefer to have general than local anaesthesia, and
TABLE VII Patient evaluation

\begin{tabular}{lccc}
\hline & $R B$ & $P B$ & $M R B$ \\
\hline During block & & & \\
- No pain & $21(42 \%)$ & $18(36 \%)$ & $30(60 \%)^{*}$ \\
- Mild pain & $29(58 \%)$ & $32(64 \%)$ & $20(40 \%)$ \\
During surgery & & & \\
- No pain & $45(90 \%)$ & $46(92 \%)$ & $50(100 \%)$ \\
- Mild pain & $5(10 \%)$ & $4(8 \%)$ & 0 \\
Would have same block again & & \\
- Yes & $49(98 \%)$ & $48(96 \%)$ & $50(100 \%)$ \\
- No & 1 & 1 & 0 \\
- Not sure & 0 & 1 & 0 \\
\hline
\end{tabular}

$* P=0.0163$ compared with $\mathrm{PB}$ group.

one patient in the PB group was not sure if she would like to have another operation on her eye at all. All patients who had the MRB would have the same anaesthetic again ( $n=\mathrm{NS}$ ).

\section{Discussion}

The choice between RB and PB for ophthalmic surgery continues to be debated. Retrobulbar block has the advantage of having a faster onset, but frequently requires supplemental facial nerve blockade or lid margin infiltration to produce orbicularis akinesia. Insertion of the needle into the muscle cone, with a change in the direction of the needle around the globe, can traumatize the globe, the optic nerve, the arteries or veins. Fortunately, in experienced hands these serious complications are rare. ${ }^{3} \mathrm{Pe}-$ ribulbar block, with insertion of the needle outside the muscle cone, can theoretically avoid advancing the needle close to these important structures. However, perforation of the globe and retrobulbar haemorrhage can still occur with the PB technique. Furthermore, PB takes a longer time to achieve optimal akinesia, and requires a larger volume of anaesthetic solution, thereby producing a higher pressure in the orbit.

Although the location and depth of needle insertion and anaesthetic deposition may account for many of these differences, operator technique may contribute considerably to the outcome. It is possible that some of the PB are in fact RB with the needle tip placed within the muscle cone.

Incomplete akinesia is a frequent problem with RB and PB. It is annoying to find that after depositing a relatively large volume of local anaesthetic solution into a small and well-confined orbital space the patient can still move the eye. In this study, solid akinesia in all muscles was obtained more often with MRB than with RB or MRB.

Hamilton et al. ${ }^{3}$ reported that block supplementation was required in $19.8 \%$ of patients after low volume RB, 
in $9 \%$ after high volume $\mathrm{RB}$ and in $24 \%$ after PB. Weiss and Deichman's experience was that supplementation was required in $21 \%$ of patients who received RB and in $28 \%$ of those who received PB. ${ }^{30}$ Our overall supplementation rate was $14.7 \%$ (MRB 8\%, PB 10\%, RB 26\%) and these rates are comparable with those reported in the literature.

Complete orbicularis akinesia was obtained in $94 \%$ of MRB, compared with $86 \%$ of PB, and only $46 \%$ of RB. Orbital rim infiltration was used to immobilize the orbicularis oculi in $30 \%$ of patients in the RB group, $2 \%$ in the PB group, and none in the MRB group. The residual orbicularis movements in three patients in the MRB group were easily blocked by the supplemental MRB or PB for concomitant extraocular muscle movements. Lid akinesia is not always obtained with either $\mathrm{RB}$ or PB. ${ }^{30}$ Martin, in a series of $50 \mathrm{RB}$ blocks, reported that the orbicularis oculi was not immobilized in $12 \%$ of cases. ${ }^{42}$ Our RB produced less favourable results, but supplemental infiltration of the orbital rim was required to immobilize the orbicularis in only one-third of our cases. On the other hand, the MRB was far superior in this regard.

The positioning of the needle for RB in the muscular cone has the potential for trauma to the globe, nerves and vascular structures. The dual superficial needle insertion in PB does not eliminate these complications. Perhaps, in these cases, the supposedly PB were in fact RB with the needle tip placed within the muscle cone. In any event, the actual incidence of serious complications is low. No serious complication occurred in the present study. In the classical RB, the inferolateral insertion of the needle to the equator of the globe and subsequent change in the needle direction behind the globe towards the orbital apex increases the chance of perforation, particularly in myopic patients with elongated globes. The straight insertion of the needle without redirection in the MRB technique should minimize this complication. Although MRB does not eliminate the potential danger of trauma to the retrobulbar structures, its simple direct approach to the muscle cone may account for its higher success rate than with the classical RB technique. The site of needle insertion in the MRB is similar to the superomedial needle insertion part of the PB. By placing the needle medially, trauma to the trochlea apparatus is avoided.

Since dramatic improvement of inadequate akinesia is unlikely by waiting longer than ten minutes, assessment of ocular movement was performed at this time. The unblinded assessment of the blocks by the anaesthetist at ten minutes after injection may be a criticism of the study protocol. This concern had been considered before starting the study because of the lack of a consistent person to do all the assessments. To minimize bias, the assess- ment was performed by two persons: the anaesthetist and his resident, or the anaesthetist and the attending nurse. The criteria of scoring helped to minimize bias. "Total akinesia" and "full movement" were definite. One might question the distinction between "a flicker of movement" and "some movement." For this study, supplemental blocks were administered to eyes with "some movement" and not to those with "a flicker of movement." The rating of the eye movements by the surgeon at surgery serves to double-check any unintentional bias.

Modified retrobulbar block, which produces a high percentage of akinesis and analgesia after a single injection, and has high patient acceptance, is an attractive alternative to RB and PB. MRB has been used in over 300 cases outside this study with no serious complications. It has become the primary technique of one of the authors for cataract surgery.

\section{References}

1 Rubin AP. Anaesthesia for cataract surgery - time for change? (Editorial) Anaesthesia 1990; 45: 717-8.

2 Fry RA, Henderson J. Local anaesthesia for eye surgery. The peri-ocular technique. Anaesthesia 1990; 45: 14-7.

3 Hamilton RC, Gimbel HV, Strunin L. Regional anaesthesia for 12,000 cataract extraction and intraocular lens implant procedures. Can J Anaesth 1988; 35: 615-23.

4 Barker JP, Robinson PN, Vafidis GC, Hart GR, SapsedByrne S, Hall GM. Local analgesia prevents the cortisol and glycaemic responses to cataract surgery. $\mathrm{Br} \mathrm{J}$ Anaesth 1990; 64: 442-5.

5 Knapp $H$. On cocaine and its use in ophthalmic and general surgery. Arch Ophthalmol 1884; 13: 402-48.

6 Ramsay RC, Knobloch WH. Ocular perforation following retrobulbar anesthesia for retinal detachment surgery. Am J Ophthalmol 1978; 86: 61-4.

7 Zaturansky B, Hyams S. Perforation of the globe during the injection of local anesthesia. Ophthalmic Surg 1987; 18: 585-8.

8 Schneider ME, Milstein DE, Oyakawa RT, Ober RR, Campo $R$. Ocular perforation from a retrobulbar injection. Am J Ophthalmol 1988; 106: 35-40.

9 Pautler SE, Grizzard WS, Thompson LN, Wing GL. Blindness from retrobulbar injection into the optic nerve. Ophthalmic Surg 1986; 17: 334-7.

10 Jindra LF. Blindess following retrobulbar anesthesia for astigmatic keratotomy. Ophthalmic Surg 1989; 20: 433-5.

11 Goldsmith $M O$. Occlusion of the central retinal artery following retrobulbar hemorrhage. Ophthalmologica 1967; 153: 191-6.

12 Kraushar $M F$, Seelenfreund $M H$, Freilich $D B$. Central retinal artery closure during orbital hemorrhage from retrobulbar injection. Transactions of the American Academy of Ophthalmology and Otolaryngology 1974; 78: 65-70. 
13 Klein ML, Jampol LM, Condon PI, Rice TA, Serjeant $G R$. Central retinal artery occlusion following retrobulbar hemorrhage after retrobulbar anesthesia. Am J Ophthalmol 1982; 93: 573-7.

14 Sullivan $K L$, Brown GC, Forman AR, Sergott RC, Flanagan JC. Retrobulbar anaesthetic and retinal vascular obstruction. Ophthalmology 1983; 90; 373-7.

15 Hersch M, Baer G, Dieckert JP, Lambert HM, Shore JW. Optic nerve enlargement and central retina-artery occlusion secondary to retrobulbar anesthesia. Ann Ophthalmol 1989; 21: 195-7.

16 Antoszyk AN, Buckley EG. Contralateral decreased visual acuity and extraocular movement palsies following retrobulbar anesthesia. Ophthalmology 1986; 93: 462-5.

17 Friedberg $H L$, Kline OR Jr. Contralateral amaurosis following retrobulbar injection. Am J Ophthalmol 1986; 101: 688-90.

18 Hamilton RC. Brain stem anesthesia following retrobulbar blockade. Anesthesiology 1985; 63: 688-90.

19 Meyers EF. Brain-stem anesthesia after retrobulbar block (Letter). Arch Ophthalmol 1985; 103: 1278.

$20 A h n J C$, Stanley JA. Subarachnoid injection as a complication of retrobulbar anesthesia. Am J Ophthalmol 1987; 103: 225-30.

21 Javitt JC, Addiego R, Friedberg HL, Libonati MM, Leahy $J J$. Brain stem anesthesia after retrobulbar block. Ophthalmology 1987; 94: 718-24.

22 Meyers EF, Ramirez RC, Boniuk I. Grand mal seizures following retrobulbar block. Arch Ophthalmol 1978; 96: 847-9.

23 Smith $J L$. Retrobulbar bupivacaine can cause respiratory arrest (Editorial). Ann Ophthalmol 1982; 14: 1005-5.

24 Wittpenn JR, Rapoza P, Sternberg P Jr, Kuwashima L, Saklad J, Patz A. Respiratory arrest following retrobulbar anesthesia. Ophthalmology 1986; 93: 867-70.

25 Kobet $K A$. Cerbral spinal fluid recovery of lidocaine and bupivacaine following respiratory arrest subsequent to retrobulbar block. Ophthalmic Surg 1987; 18: 11-3.

26 Rosenblatt RM, May DR, Barsoumian K. Cardiopulmonary arrest after retrobulbar block. Am J Ophthalmol 1980; 90; 425-7.

27 Feibel RM. Current concepts in retrobulbar anesthesia. Surv Ophthalmol 1985; 30: 102-10.

28 Bloomberg LB. Administration of periocular anesthesia. J Cataract Refract Surg 1980; 12: 677-9.

29 Davis DB II, Mandel MR. Posterior peribulbar anesthesia: an alternative to retrobulbar anesthesia. J Cataract Refract Surg 1986; 12: 182-4.

30 Wiess $J L$, Deichman $C B$. A comparison of retrobulbar and periocular anesthesia for cataract surgery. Arch Ophthalmol 1989; 107: 96-8.

31 Davis DB II, Mandel MR. Peribulbar anesthesia: a review of technique and complications. Ophthalmology Clinics of North America 1990; 3: 101-10.

32 Kimble JA, Morris RE, Witherspoon CD, Feist RM. Globe perforation from peribulbar injection (Letter). Arch Ophthalmol 1987; 105: 749.

33 Hay A, Flynn HW Jr, Hoffman JI, Rivera AH. Needle penetration of the globe during retrobulbar and peribulbar injections. Ophthalmology 1991; 98: 1017-24.

34 Duker JS, Belmont JB, Benson WE, et al. Inadvertent globe perforation during retrobulbar and peribulbar anesthesia. Patient characteristics, surgical management, and visual outcome. Ophthalmology 1991; 98: 519-26.

35 Grizzard WS, Kirk NM, Pavan PR, Antworth MV, Hammer $M E$, Roseman $R L$. Perforating ocular injuries caused by anesthesia personnel. Ophthalmology 1991; 98 : 1011-6.

36 Feitl ME, Krupin T. Neural blockade for ophthalmologic surgery. In: Cousins JM, Bridenbaugh PO (Eds.). Neural Blockade in Clinical Anesthesia and Management of Pain, 2nd ed., Philadelphia: J.B. Lippencott Co., 1988; 577-592.

37 Straus JG. A new retrobulbar needle and injection technique. Ophthalmic Surg 1988; 19: 134-9.

38 Davis DB II, Mandel MR. Peribulbar vs retrobulbar anesthesia. Straus JG. Response by Dr. Straus (Letter). Ophthalmic Surg 1988; 19: 529-31.

39 Hagan JC III. Peribulbar vs retrobulbar anesthesia (Letter). Ophthalmic Surg 1988; 19: 143-4.

40 Pannu JS. Peribulbar vs retrobulbar anesthetic techniques (Letter). Ophthalmic Surg 1990; 21: 147-9.

41 Straus JG. Peribulbar vs retrobulbar anaesthetic techniques (Letter). Ophthalmic Surg 1990; 21: 149-50.

42 Martin SR, Baker SS, Muenzler WS. Retrobulbar anesthesia and orbicularis akinesia. Ophthalmic Surg 1986; 17: 232-3. 